\title{
MAGNESIUM URINARY EXCRETION IN DIABETIC ADOLESCENTS
}

\author{
Žaneta Drižiene ${ }^{1}$, Donatas Stakisaitis ${ }^{2}$, Janina Balsiene ${ }^{3}$
}

Vilnius University, Medical Faculty, Lithuania: Centre of Pediatrics ${ }^{1}$, Institute of Oncology ${ }^{2}$; M. Romeris University, Lithuania: Study Center for Central and Eastern Europe ${ }^{3}$

\begin{abstract}
Summary: Objective: to define peculiarities of urinary magnesium $(\mathrm{Mg})$ excretion in diabetic adolecents; to elucidate gender-related differences in $\mathrm{Mg}$ urinary excretion; to determine urinary $\mathrm{Mg}$ excretion differences between diabetic and age-matched healthy children. The diurnal, nocturnal and 24-h urinary Mg level in adolescent boys and girls (aged 13-17 years) with type I diabetes mellitus (DM) and in age-matched control groups of healthy boys and girls was examined. Additionally the adolescent girls were examined during different phases of their menstrual cycle. Results: Diurnal, overnight and 24-h Mg urinary excretion in diabetic adolescent boys and girls was significantly higher than in healthy ones. In diabetic boys $24 \mathrm{~h} \mathrm{Mg}$ excretion was higher than in diabetic girls (4.59 \pm 1.4 vs. $3.34 \pm 1.5 \mathrm{mmol}$; $\mathrm{p}<0.05$ ). The investigation showed gender-related differences in $\mathrm{Mg}$ urinary excretion in healthy adolescents: $24-\mathrm{h} \mathrm{Mg}$ urinary excretion was significantly higher in boys than in girls $(2.66 \pm 0.9$ vs. $2.1 \pm 0.9 \mathrm{mmol} ; \mathrm{p}<0.05)$. The level of $\mathrm{Mg}$ in the nocturnal urine of boys and girls was significantly higher than in diurnal. Urine $\mathrm{Mg}$ was negatively related to height in adolescent girls. Conclusion: Diabetic adolescents excrete significantly more $\mathrm{Mg}$ with urine as compared to healthy ones.
\end{abstract}

Key words: Adolescent; Magnesium; Gender; Menstrual cycle; Diabetes mellitus

\section{Introduction}

Current epidemiological, clinical and experimental data suggest that the pathogenesis of primary arterial hypertension may be gender-related. Men tend to have a higher predisposition to hypertension (19). The same antihypertensive treatment has different efficacy in men and women $(43,27)$. Decreased blood and tissue magnesium $(\mathrm{Mg})$ may predispose to arterial hypertension (4). Experimental data show that the increased gender-dependent vascular reactivity may be related to changes in extracellular or intracellular $\mathrm{Mg}$ ion level $(1,48,16)$. Clinical data concerning $\mathrm{Mg}$ effects on blood pressure are highly contradictory (14). Higher $\mathrm{Mg}$ urinary excretion may predispose to $\mathrm{Mg}$ depletion in hypertensive subjects (26). Our previous investigations had revealed changes in $\mathrm{Mg}$ urinary excretion in hypertensive adolescent boys: 24- $\mathrm{h} \mathrm{Mg}$ urinary excretion was found significantly higher in hypertensive than in normotensive adolescent boys (42).

Hypermagnesuria is not related to blood $\mathrm{Mg}$ concentration (5). Studies in children failed to reveal a statistically significant dependence of urinary $\mathrm{Mg}$ excretion on $\mathrm{Mg}$ intake with food (46). No clear dependence was found between $\mathrm{Mg}$ excretion and $\mathrm{Mg}$ intake with medicinal preparations in adult subjects either (6).

In diabetic patients, $\mathrm{Mg}$ levels in bones and muscles, as well as in erythrocytes are decreased $(10,41)$. Hypomagne- semia in diabetes mellitus (DM) patients can be related not only to inclination to hypertension, but also to the development of diabetic angiopathy $(31,32)$. Low concentrations of ionised $\mathrm{Mg}$ in blood serum is characteristic of DM children (20).

In this article, we have presented data on diurnal, nocturnal, and 24-h Mg excretion in DM adolescents of both sexes. We have investigated whether $\mathrm{Mg}$ excretion is dependent on day and night variability. The control group of girls was examined during the different fases of their menstrual cycle.

\section{Materials and methods}

Mg urinary level was investigated in 23 adolescent boys and 32 adolescent girls aged 13 through 17 years with type I diabetes mellitus. The children were treated with insulin. DM had been diagnosed no less than 6 months before study. The patients attend the hospital diabetic clinic for full clinical and biochemical assessment. In all patients before recruiting DM had been compensated for no less than two months; their received standard care with adjusted insulin dosage. Within the study period, no concomitant diseases were diagnosed in the children. No diabetic children with retinopathy, chronic renal lesion, microalbuminuria, proteinuria were enrolled, and all patients had a normal serum creatinine level. 
In diabetic girls and boys the diurnal diuresis was: $0.96 \pm 0.51$ (duration $14.8 \pm 0.9 \mathrm{~h}$ ) in girls and $1.1 \pm 0.61$ in boys $(14.6 \pm 0.8 \mathrm{~h})$, nocturnal $0.58 \pm 0.31$ (duration $9.2 \pm 0.9 \mathrm{~h}$ ) and $0.65 \pm 0.31(9.4 \pm 0.8 \mathrm{~h})$, respectively. DM duration in girls was $5.9 \pm 3.7$ and in boys $6.3 \pm 3.8$ years. The diabetic adolescents' body weight and BMI are presented in Tab. 1 .

$\mathrm{Mg}$ was monitored in the diurnal and nocturnal urine of healthy postpubertal boys $(n=27)$ and girls $(n=42)$ aged 13-17 years (Tab. 1). The control groups comprised agedmatched children with no consideration to their sexual maturity level. The children received no special food or liquid diets, their physical activity was usual. The study groups contained no adolescents actively going in for sports. Urine was collected according to the accepted procedure. The children were advised to keep regular sleeping hours: to go to bed at about 9-10 p.m. and to get up at about 7-8 a.m. Diurnal urine was collected throughout the day, excluding the first urination after awakening in the morning and including the last urination before going to bed. Nocturnal urine was collected during the first urination just upon awakening in the morning and during awakenings at night if necessary. The diurnal diuresis was $0.5 \pm 0.31$ (duration $13.6 \pm 1.3 \mathrm{~h})$ in girls and $0.49 \pm 0.251$ in boys $(13.7 \pm 1.7 \mathrm{~h})$, nocturnal diuresis being $0.29 \pm 0.151$ (duration $10.4 \pm 1.3 \mathrm{~h}$ ) and $0.3 \pm 0.21(10.3 \pm 1.7 \mathrm{~h})$, respectively.

Additionally urinary $\mathrm{Mg}$ excretion in healthy adolescent girls $(n=15$, mean age $14.8 \pm 0.9)$ was monitored in different phases of their menstrual cycle. All the girls, who had regular menstrual cycles, were monitored on the days including the $5^{\text {th }}$ day (during the follicular phase, when estrogen and progesterone levels were close to minimal), on the $13^{\text {th }}$ day (during the ovulation phase, when estrogen level was maximal), and on the $20^{\text {th }}$ day (during the luteal phase, when progesterone level was close to maximal).

Urinary $\mathrm{Mg}$ concentration was tested by spectrophotometry, using special kits for Mg investigation (Aqua-Medica, Poland).

The impact of various factors on $\mathrm{Mg}$ excretion was investigated by means of correlation analysis. Student's t test was used to show the significance of the data.

Permission to carry out the study was obtained from the Lithuanian Bioethics Committee (Protocol No. 01-35; 11.07.2001).

\section{Results}

Magnesium urinary concentration and excretion in control groups. We have found that 24-h urinary excretion of $\mathrm{Mg}$ in boys was significantly higher as compared to girls (Tab.1). This difference was not related to diuresis. No significant differences in the day, night and 24-h urine volume of girls and boys were determined ( $p>0.05)$. The level of $\mathrm{Mg}$ in the nocturnal urine of boys and girls was significantly higher as compared to the $\mathrm{Mg}$ level in diurnal urine (3.2 \pm 0.7 vs. $2.5 \pm 0.6 \mathrm{mmol} / \mathrm{l} ; \mathrm{p}<0.05$ in boys; and $2.9 \pm 0.7$ vs. $2.3 \pm 0.9 \mathrm{mmol} / 1 ; \mathrm{p}<0.05$ in girls, respectively).

There was a significant correlation between 24-h $\mathrm{Mg}$ urinary excretion and height $(r=-0.34 ; p<0.05)$ in healthy adolescent girls. This relationship was absent in age-matched boys $(\mathrm{r}=0.10 ; \mathrm{NS})$.

Magnesium urinary level and excretion in DM patients. Diurnal, overnight and 24-h Mg excretion in diabetic boys was higher than in diabetic girls (Tab. 1). This difference was not related to diuresis (no significant differences in the day, night and 24-h urine volume of girls and boys were determined, $\mathrm{p}>0.05$ ).

The $\mathrm{Mg}$ level in the nocturnal urine was significantly higher compared to the diurnal urine of diabetic boys and girls ( $3.5 \pm 1.2$ vs. $2.6 \pm 0.7 \mathrm{mmol} / 1 ; \mathrm{p}<0.05$ in boys; and $3.0 \pm 0.9$ vs. $2.3 \pm 0.9 \mathrm{mmol} / 1 ; \mathrm{p}<0.05$ in girls, respectively).

Daily urinary $\mathrm{Mg}$ was positively related to weight both in DM boys and girls $(r=0.40$ and $r=0.37$ respectively; $\mathrm{p}<0.05)$ as well as to body mass index (BMI) ( $\mathrm{r}=0.37$ and $r=0.42$ respectively; $p<0.05$ ).

Diurnal, overnight and 24-h Mg urinary excretion in diabetic boys and girls was significantly higher than in healthy ones (Tab. 1). First of all it was related to diuresis - the diurnal, nocturnal and 24-h volume of urine in diabetic girls and boys was significantly greater than in healthy ones $(\mathrm{p}<0.05)$. The $\mathrm{Mg} /$ creatinine ratio in diurnal and nocturnal urine in diabetic girls and boys was significantly higher than in healthy ones $(\mathrm{p}<0.05)$. The distribution according to $\mathrm{Mg}$ excretion level in the groups of healthy and DM children is shown in Fig. 1.

24-h urinary $\mathrm{Mg}$ excretion per kilogram of body weight in diabetic girls was definitely higher than in healthy girls $(0.065 \pm 0.01$ vs. $0.04 \pm 0.02 ; \mathrm{p}<0.01)$. The difference was de-

Tab. 1: Height, body weight and $\mathrm{Mg}$ excretion in urine data of examined adolescents.

\begin{tabular}{|c|c|c|c|c|c|c|}
\hline $\begin{array}{c}\text { Investigated } \\
\text { adolescents groups }\end{array}$ & \multirow{2}{*}{} & \multirow{2}{*}{$\begin{array}{c}\text { Height } \\
(\mathrm{cm})\end{array}$} & \multirow{2}{*}{ BMI } & \multicolumn{3}{|c|}{ Urinary excretion of Mg (mmol) } \\
\cline { 5 - 7 } & & & Diurnal & Nocturnal & $24-\mathrm{h}$ \\
\hline Healthy boys & 27 & $174.2 \pm 8.2$ & $19.9 \pm 2.2$ & $1.45 \pm 0.7$ & $1.19 \pm 0.5$ & $2.66 \pm 0.9^{*}$ \\
\hline Healthy girls & 42 & $165.2 \pm 6.4$ & $20 \pm 20.1$ & $1.23 \pm 0.6$ & $0.88 \pm 0.4$ & $2.1 \pm 0.9^{*}$ \\
\hline Diabetic boys & 23 & $169.2 \pm 7.1$ & $20.4 \pm 3.6$ & $2.59 \pm 1.2 \boldsymbol{\nabla}$ & $2.0 \pm 0.8 \boldsymbol{\nabla}$ & $4.59 \pm 1.4 \boldsymbol{\nabla}$ \\
\hline Diabetic girls & 32 & $163.2 \pm 3.2$ & $20 \pm 3$ & $1.9 \pm 1.1 \boldsymbol{\nabla}$ & $1.5 \pm 0.8 \boldsymbol{\nabla}$ & $3.34 \pm 1.5 \boldsymbol{}$ \\
\hline
\end{tabular}

* $-\mathrm{p}<0.05$, healthy boys versus healthy girls

$\boldsymbol{\nabla}-\mathrm{p}<0.05$, DM boys versus DM girls 
termined by comparing this index in diabetic and healthy boys $(0.085 \pm 0.03$ vs. $0.04 \pm 0.01 ; p<0.01)$. In diabetic boys, urinary $\mathrm{Mg}$ excretion per kilogram of body weight within 24-h was significantly higher than in diabetic girls $(0.085 \pm 0.03$ vs. $0.065 \pm 0.01 ; p<0.01)$.

Girls of DM group exhibited a significant inverse correlation between 24-h $\mathrm{Mg}$ excretion and duration of the disease $(r=-0.48 ; \mathrm{p}<0.05)$. Such relationship was not characteristic of boys $(\mathrm{r}=-0.14$; NS). No significant correlation between 24-h Mg excretion and 24-h insulin dose was determined in the study groups of boys and girls ( $\mathrm{r}=-0.14$; NS in boys and $r=0.14$; NS in girls).

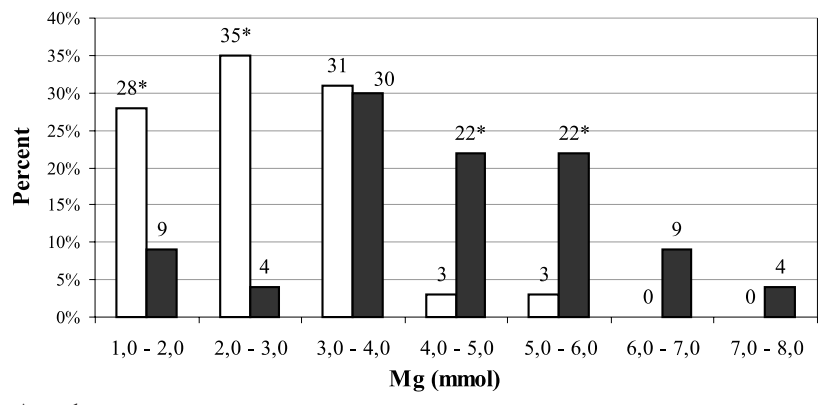

$$
\text { A - boys } \square \text { Healthy boys Diabetic boys }
$$

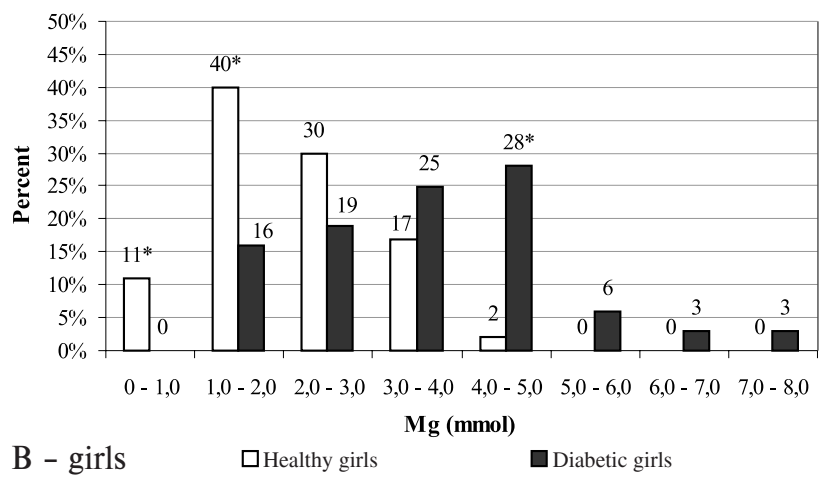

Fig. 1: Distribution of urinary $\mathrm{Mg}$ excretion in the groups of healthy and diabetic adolescent. ${ }^{*}-\mathrm{p}<0.05$, compared data for healthy and diabetic subjects.

\section{Discussion}

Current knowledge suggests that $\mathrm{Mg}$ depletion may be involved in the pathogenesis of essential hypertension (34, 14). Clinical evidence indicates $\mathrm{Mg}$ supplementation sometimes to be a useful adjunct to the treatment of hypertension (26).

In DM patients, enhanced Mg excretion may be caused by 1) hyperglycemia and hyperglucosuria, which act as osmotic diuresis; 2) metabolic acidosis, which induces $\mathrm{Mg}$ excretion in the distal tubules (36); 3) hypophosphatemia and hypokalemia, which reduce $\mathrm{Mg}$ absorption in the loop of Henle and the distal tubule (9). Insulin enhances urine accumulation in the thick ascending limb of the loop of Henle $(9,30)$. Therefore increased $\mathrm{Mg}$ excretion is also related to insulin deficiency. DM children usually show a lowered ionised $\mathrm{Mg}$ concentration in blood serum, which is a sign of $\mathrm{Mg}$ depletion in the body (20).

Investigation of gender-related differences in $\mathrm{Mg}$ turnover may explain the higher prevalence of hypertension in men, as well as some mechanisms involved in the progression of this disease, and in diabetics, as an important risk group of essential hypertension. Some changes capable of contributing to hypertension in adulthood may be found in childhood.

Gender-related Mg turnover peculiarities in healthy subjects. We have found that 24-h urinary Mg excretion in adolescent boys is significantly higher than in adolescent girls. Differences in both 24-h urinary excretion and urinary level of $\mathrm{Mg}$ may result from gender-related physiological differences in its turnover. Magnesium balance depends on renal excretion, which is regulated mainly in the thick ascending limb of Henle's loop (23). Experimental data show age- and gender-related differences in reabsorption of $\mathrm{Mg}$ and calcium ions in renal tubules, but molecular mechanisms of such differences are still unclear (45).

Examination of serum $\mathrm{Mg}$ in children and adults did not show gender-related differences $(21,40,2)$. Increased urinary $\mathrm{Mg}$ was not found to be associated with hypermagnesemia (5). Extensive trials did not show any significant correlation between urinary excretion and dietary intake of $\mathrm{Mg}$ in children (46). No correlation between the dose of oral $\mathrm{Mg}$ supplementation and urinary excretion of $\mathrm{Mg}$ in adults was found (6). Therefore some other gender-related factors and mechanisms were supposed to be involved in renal excretion of $\mathrm{Mg}$ and its depletion.

Depletion of $\mathrm{Mg}$ may be associated with relative insulin resistance, impaired glucose tolerance and hyperinsulinemia in normal subjects (37). Physiological doses of insulin markedly increase renal $\mathrm{Mg}$ excretion (12). It is known that there are gender-related differences in insulin resistance of cells and tissues. Insulin resistance is higher in men than and women (17).

There are gender-related differences in tissue Mg. Magnesium content in the girls' hair is significantly higher as compared to the boys' hair (25). Muscle Mg levels are significantly higher in women than in men (38). The reasons for such differences have not been disclosed yet, but they may be associated with the above-mentioned gender-related differences in $\mathrm{Mg}$ urinary excretion.

It has been clearly established that the observed circadian rhythm of blood pressure coincides with a rhythmic release of catecholamines (47). There are data showing the dependence of $\mathrm{Mg}$ urinary excretion on the activity of the sympatic nervous system (7), which is higher in men than in women (3). Therefore gender-related differences in diurnal and nocturnal blood pressure may be associated with $\mathrm{Mg}$ excretion differences in adolescent boys and girls (22). 
Clinical evidence showed serum-ionised and total $\mathrm{Mg}$ to be significantly lower during the luteal phase than in the follicular and the ovulation phases of the menstrual cycle (33). Placebo-controlled clinical trials showed hormone replacement therapy with estrogens and progesterone producing a significant decrease in urinary excretion of magnesium (39). We failed to find any literature data on physiological mechanisms of the effect of female sex hormones on renal $\mathrm{Mg}$ excretion. Ovarectomy and estrogen supplementation had no effect on intestinal $\mathrm{Mg}$ absorption in female rats (8). Girls exhibited a significant negative correlation between 24-h urinary excretion of $\mathrm{Mg}$ and height. Height may be a risk factor of hypertension in boys $(28,13)$.

There is a clear-cut evidence of a relationship between calcium and $\mathrm{Mg}$ homeostasis, and there are known genderrelated differences in calcium transport across the cell membrane, metabolism, and excretion $(18,45,24)$. Diurnal and nocturnal calcium urinary excretion differs in men and women. This phenomenon may be associated with genderrelated circadian changes in serum growth hormone and parathyroid hormone (15). Growth hormone increases the urinary excretion of magnesium (29). A possible association between gender-related differences in calcium homeostasis and Mg excretion cannot be ruled out.

Investigation of mechanisms of the above-mentioned gender-related differences in children may explain predisposition to $\mathrm{Mg}$ deficiency-related conditions in adult males. These mechanisms can also suggest prophylactic means of $\mathrm{Mg}$ deficiency-related essential hypertension.

Mg turnover peculiarities in Type I DM patients. The study has shown that urinary $\mathrm{Mg}$ excretion levels in DM girls' and boys' diurnal, nocturnal and circadian urine are reliably higher than in healthy adolescents. First of all this is related to a significantly higher diuresis of DM postpubertal children compared to the control group. Mg excretion level in diurnal urine of DM girls and boys showed a direct correlation with body weight and BMI, which was not defined in healthy ones. $\mathrm{Mg}$ excretion per kilogram of body weight in DM girls and boys was significantly higher than in healthy adolescents. Besides, the $\mathrm{Mg} /$ creatinine ratio in the diurnal, nocturnal and circadian urine of DM girls and boys was reliably higher than in healthy girls and boys. The higher $\mathrm{Mg}$ excretion in DM patients can be related to a number of factors. In DM patients, glucosuria disturbs the renal tubular reabsorption of cation from glomerular filtrate. However, in the presence of aglucosuria $\mathrm{Mg}$ excretion with urine in DM children remains abnormally high (35). It is a well-known fact that in DM children are increased glomerular filtration rate, however with no effect on $\mathrm{Mg}$ excretion $(35,44)$.

$\mathrm{Mg}$ excretion in diurnal, nocturnal and 24-h urine was reliably higher in DM boys than in DM girls. We failed to find analogous data on $\mathrm{Mg}$ urinary excretion in DM children and its relation to gender. However, there were reports on a clearly reliably direct correlation between $\mathrm{HbA}_{1}$ and $\mathrm{Mg}$ excretion in adult female patients with compensated
DM, though this correlation was not characteristic of analogous male patients (4).

DM girls exhibit an inverse correlation between $\mathrm{Mg}$ excretion and duration of the disease. Other authors report that $\mathrm{Mg}$ excretion also depends on the administered dose of insulin (12).

In spite of maintaining a normal blood glucose concentration, hypomagnesemia has been diagnosed in 25 per cent of patients (20). $\mathrm{Mg}$ turnover derangements and $\mathrm{Mg}$ deficiency in DM patients can be one of the reasons for arterial hypertension in diabetic patients (11).

\section{Conclusion}

Adolescent boys and girls ill with diabetes mellitus showed a significantly higher level of diurnal, overnight and 24-h urinary excretion than healthy ones. Diabetic girls and boys showed a direct relation of diurnal $\mathrm{Mg}$ excretion to body weight and body mass index. The higher $\mathrm{Mg}$ excretion might be indicative of a higher risk of $\mathrm{Mg}$ depletion.

\section{References}

1. Altura BM, Altura BT. Magnesium and cardiovascular biology an important link between cardiovascular risk factors and atherogenesis. Cell Mol Biol Res 1995; 41:347-9.

2. Bohnen N, Degenaar CP, Joless J. Influence of age and sex on 19 blood variables in healthy subjects. Z Gerontol 1992; 25:339-45.

3. Bowyer L., Brown MA, Jones M. Vascular reactivity in men and women of reproductive age. Am J Obstet Gynecol 2001; 185:88-96.

4. Brown IR, McBain AM, Chalmers J et al. Sex difference in the relationship of calcium and magnesium excretion to glycaemic control in type 1 diabetes mellitus. Clin Chim Acta 1999; 283:119-28.

5. Chen MD, Lin PY, Tsou CT et al. Selected metals status in patients with noninsulin-dependent diabetes mellitus. Biol Trace Elem Res 1995; 50:119-24.

6. Cielinski G, Albert W, Schauermann E, Kober G. Magnesium excretion in urine is not a marker of magnesium deficiency. Reliability of an oral magnesium administration test. Med Klin 1999; 94:82-7.

7. Corica F, Corsonello A, Buemi M et al. Platelet magnesium depletion in normotensive and hypertensive obese subjects: the role of salt-regulating hormones and catecholamines. Magnes Res 1999; 12:287-95.

8. Coudray $\mathrm{C}$, Gaumet $\mathrm{N}$, Bellanger $\mathrm{J}$ et al. Influence of age and hormonal treatment on intestinal absorption of magnesium in ovariectomised rats. Magnes Res 1999; 12:109-14.

9. Dai LJ, Ritchie G, Kerstan D et al. Magnesium transport in the renal distal convoluted tubule. Physiological Review 2001; 81:51-84.

10. De Leew I, Vertommen J, Abs R. The magnesium content of the trabecular bone in diabetic subjects. Biomedicine 1978; 29(1):16-7.

11. Djurhus MS, Henriksen JE, Klitgaard NA. et al. Effect of moderate improvement in metabolic control on magnesium and lipids concentrations in patients with type 1 diabetes. Diabetes care 1999; 22:546-54

12. Djurhus MS, Skott P, Hother-Nielson O et al. Insulin increases renal magnesium excretion: a possible cause of magnesium depletion in hyperinsulinaemic states. Diabet Med 1995; 12:664-9.

13. Duarte JA, Guerra SC, Ribeiro JC, Mota RC. Blood pressure in pediatric years (8-13 years old) in the Oporto region. Rev Cardiol Portugal 2000; 19:809-20.

14. Durlach J, Durlach V, Rayssinguier Y et al. Magnesium and blood pressure. Clinical studies. Magnes Res 1992; 29:147-53.

15. Eastell R, Calvo MS, Burritt MF et al. Abnormalities in circadian patterns of bone resorption and renal calcium conservation in type I osteoporosis. J Clin Endocrinol Metab. 1992;74:487-94.

16. Ema M, Gebrewold A, Altura BT, Altura BM. Magnesium sulphate prevents alcohol induced spasms of cerebral blood vessels and in situ study on the brain microcirculation from male versus female rats. Magnes Trace Elem 1991-92; 10: 269-80.

17. Foley JE, Kashivagi A, Chang $\mathrm{H}$ et al. Sex differences in insulin-stimulated glucose transport in rat and human adipocytes. Am J Physiol 1984; 246:E211-15.

18. Gafter U, Malachi T, Barak H, Levi J. Red blood cell calcium level is elevated in women: enhanced calcium influx by estrogens. J Lab Clin Med 1993; 121: 486-92. 
19. Hinojosa-Laborde C, Chapa I, Lange D, Haywood JR. Gender differences in sympathetic nervous regulation. Clin Exp Pharmacol Physiol 1999; 26:122-6.

20. Husmann MJ, Fuchs P, Truttmann AC et al. Extracellular magnesium depletion in pediatric patients with insulin-dependent diabetes mellitus. Miner Electrolyte Metab 1997; 23:121-4.

21. Jagarinec N, Flegar-Mestric Z, Surina B et al. Pediatric reference intervals for 34 biochemical analytes in urban school children and adolescents. Clin Chem Lab Med 1998; 36:327-37.

22. Jankunas R, Driziene Z, Stakisaitis D, Kuliesiene I. Gender-dependent magnesium urinary excretion in healthy adolescents and adults. Acta medica Lituanica. 2001 3. $167-172$

23. Kelepouris E, Agus ZS. Hypomagnesemia: renal magnesium handling. Sem Nephrol 1998; 18:58-73.

24. Kesteloot H, Lesaffre E. On the sex ratio of urinary cation excretion obtained from INTERSALT and other epidemiologic studies. J Human Hypertens 1990; 603-7.

25. Kozielec T, Drybanska-Kolita A, Hornovska I, Salacka A. Levels of calcium, magnesium, zinc, copper and iron in hair of children and adolescents. Pol Merkeriusz Lek 1996; 1:150-4

26. Laurant P, Touyz RM. Physiological and pathophysiological role of magnesium in the cardiovascular system: implications in hypertension. J Hypert 2000; 18:1177-91.

27. Lunet N, Barros H. Gender differences in the treatment of Hypertension: a com munity based study in Porto. Rev Port Cardiol 2002; 21:7-19.

28. Lurbe E, Cremades B. Torro I et al. Gender modifies the relationship between awake systolic blood pressure and growth in adolescents. Am J Hypertens 1998; $11: 21 \mathrm{~A}$.

29. Mahlbacher K, Sicuro A, Gerber H et al. Growth hormone corrects acidosis-induced renal phosphate depletion and attenuates renal magnesium wasting in humans. Metabolism 1999; 48:763-70.

30. Mandon B, Siga E, Chabardes D et al. Insulin stimulates $\mathrm{Na}^{+}, \mathrm{Cl}-, \mathrm{Ca}^{2+}$, and $\mathrm{Mg}^{2+}$ transports in TAL of mouse nephron: cross-potentiation with ADH. Am J Physiol Renal Fluid Electrolyte Physiol 1993; 265: F361-9.

31. McNair P, Christiansen C, Madsbad S et al. Hypomagnesemia, a risk factor in diabetic retinopathy. Diabetes 1978; 27:1075-7.

32. McNair P, Madsbad S, Christiansen C et al. Bone loss in diabetes: effects of metabolic state. Diabetologia 1979; 17:283-6.

33. Muneyvirci-Delale O, Nacharaju VL, Altura BM, Altura BT. Sex steroid hormones modulate serum ionized magnesium and calcium levels throughout the menstrual cycle in women. Fertil Steril 1998; 69:958-62.

34. Ozono R, Oshima T, Matsura $\mathrm{H}$ et al. Systemic magnesium deficiency disclosed by magnesium loading test in patients with essential hypertension. Hypertens Res $1995 ; 18: 39-42$

35. Ponder SW, Brouhard BH, Travis LB. Hyperphosphaturia and hypermagnesuria in children with IDDM. Diabetes Care 1990; 13:437-40.

36. Quamme GA. Renal magnesium handling: new insights in understanding old problems. Kidney Int 1997; 52:1180-95.
37. Rosolova H, Mayer O Jr, Reaven G. Effect of variations in plasma magnesium concentration on resistance to insulin-mediated glucose disposal in nondiabetic subjects. J Clin Endocrinol Metab 1997; 82:3783-5.

38. Rubenowitz E, Landin K, Wilhelmsen L. Skeletal muscle magnesium and potassium by gender and hypertensive status. Scand J Clin Lab Invest 1998; 58:47-54.

39. Schemmer A, Podenphant J, Riis BJ, Christiansen C. Urinary magnesium in early postmenopausal women. Influence of hormone therapy on calcium. Magnes Trace Elem 1991-1992; 10:34-9.

40. Sherwani S, Hasnain N, Qodir-Uddin A. Magnesium status in maternal and cord blood. JPMA J Pak Med Assoc 1998; 48:32-4.

41. Sjogren A, Floren $\mathrm{CH}$, Nilsson A. Oral administration of magnesium hydroxide to subjects with insulin-dependent diabetes mellitus: effect on magnesium and potassium levels and on insulin requirements. Magnesium 1988; 7:117-22.

42. Stakisaitis D, Driziene Z, Jankunas R, Kuliesiene I. Urinary magnesium in normotensive and hypertensive adolescents. Cardiovascular diseases 2002, Monduzzi Editore Internatinal Proceedings Division (Editors: Mitro P, Pella D, Rybar R, Valočik G); 2002: 23-27.

43. Stakisaitis D, Jankunas R, Volbekas V. Sodium, gender, and blood pressure. A review. Medicina 2000; 36:1015-22.

44. Wiseman MJ, Saunders AJ, Keen H, Viberti GC. Effect of blood glucose concentration on increased glomerular filtration rate and kidney size in insulin dependent diabetes mellitus. N England J Med 1985; 312:617-21

45. Wittner M, Desfleurs E, Pajaud S et al. Calcium and magnesium transport in the cortical thick ascending limb of Henle's loop: influence of age and gender. Pflugers Archiv-Europ J Physiol 1997; 434:451-6.

46. Wu Y, Cai R, Zhou B, Xu X. Effects of genetic factors and dietary electrolytes on blood pressure of rural secondary school students in Hanzhong. Clin Med Sci J 1991; 6: 148-52.

47. Yamasaki F, Scwartz JE, Gerber LM. Impact of shift work and race/ethnicity on the diurnal rhythm of blood pressure an catecholamines. Hypertension 1998 . $32: 417-23$

48. Zhang A, Altura BT, Altura BM. Endothelial-dependent sexual dimorphism in vascular smooth muscle: role of $\mathrm{Mg}^{2+}$ and $\mathrm{Na}^{2+}$. $\mathrm{Br} \mathrm{J}$ Pharmacol 1992; 72 194-202.

Submitted April 2005.

Accepted August 2005.

Dr. Donatas Stakisaitis,

Vilnius University, Medical Faculty,

Polocko 2, LT-2001, Vilnius,

Lithuania.

e-mail: donatasstakisaitis@VVKT.LT 